\title{
Existe lugar para a angústia no hospital? Um olhar sobre a equipe de saúde
}

\author{
Is there a place for anguish in the hospital? A look at the health team
}

DOI: $10.46919 / \operatorname{archv1n5-019}$

Recebimento dos originais: 10/07/2020

Aceitação para publicação: 30/08/2020

\section{Marcella Corrêa Laboissière}

Psicóloga. Psicanalista. Especialista em Psicologia Clínica pela PUC-RIO. Especialista em Psicologia Médica e Saúde Mental pela Faculdade de Ciências Médicas do Hospital Universitário Pedro Ernesto FCM/HUPE/UERJ. Mestre em Psicanálise pela UERJ. Doutoranda em Psicologia Clínica e Cultura pela UNB. Membro da Escola de Psicanálise dos Fóruns do Campo Lacaniano - EPFCL/Brasil.

E-mail: marcellacl@gmail.com

\section{Elisa Aires Leite}

Psicóloga. Especialista em Psicologia Médica e Saúde Mental pela Faculdade de Ciências Médicas do Hospital Universitário Pedro Ernesto - FCM/HUPE/UERJ. Mestre em Temas de Psicologia pela Faculdade de Psicologia e Ciências da Educação da Universidade do Porto.

E-mail: elisaaires@yahoo.com.br

\section{Mônica Schiller d'Escragnolle Taunay}

Psicóloga do HUPE/UERJ. Psicanalista -Sociedade Brasileira de Psicanálise do Rio de Janeiro. Especialista em Psicologia Médica - FCM/UERJ. Mestre em Saúde Coletiva - IMS/UERJ.

E-mail: mtaunay@ig.com.br

\section{RESUMO}

Esta pesquisa parte da atividade prática de Interconsulta realizada nos anos de 2015 e 2016 no Hospital Universitário Pedro Ernesto, hospital-escola da Universidade do Estado do Rio de Janeiro - UERJ. A Interconsulta consiste em uma atividade que, a partir do pedido de parecer elaborado pela equipe, após apreender alguma questão de ordem subjetiva do paciente ou da família, demanda-se o acompanhamento do profissional da psicologia. Assim, recebemos a demanda para G.J, 75 anos, diagnosticado com Linfoma Cutâneo das Células T. No atendimento, entendemos forte angústia na equipe de saúde, o que sinalizava que o pedido de escuta não se restringia ao paciente que, no presente momento, encontrava-se fora de cuidados terapêuticos. O psicólogo dentro do hospital geral é o responsável pela escuta minuciosa de cada caso, criando espaço e abrindo possibilidades para que as falas do paciente, da família e da equipe surjam. Neste trabalho foi feito um recorte nessa tríade, dando ênfase à equipe. A abordagem da investigação caracteriza-se por salientar a escuta do profissional de saúde mental em uma equipe multiprofissional como diferencial no tratamento. Realizou-se uma pesquisa qualitativa, elegendo a observação e a escuta analítica da equipe de saúde. A oferta de tratamento da Psicologia Médica e o olhar singular da Psicanálise operam como contribuição para o contexto hospitalar e para o âmbito da saúde.

Palavras-chave: Angústia, Hospital geral, Equipe de saúde, Psicologia Médica, Psicanálise.

\section{ABSTRACT}

This research is part of the practical activity of Interconsultation carried out in the years 2015 and 2016 at Hospital Universitário Pedro Ernesto, teaching hospital of the Rio de Janeiro State University - UERJ. Interconsultation consists of an activity that, following the request for a technical opinion by the team, 
after apprehending some subjective question from the patient or family, the psychology professional is required to be monitored. Thus, we received the demand for GJ, 75 years old, diagnosed with Cutaneous T-Cell Lymphoma. In the service, we noticed a strong anguish in the health team, which signalized that the listening request was not restricted to the patient who, at that moment, was itself out of therapeutic care. The psychologist inside the general hospital is responsible for listening carefully to each case, creating space and opening possibilities for the speeches of the patient, family and team to emerge. In this study, a cut was made in this triad, emphasizing in the team. The research approach is characterized by highlighting the listening of the mental health professional in a multidisciplinary team as a differential in the treatment. A qualitative research was carried out, choosing the observation and analytical listening of the health team. The medical Psychology treatment offer and the unique look of Psychoanalysis operate as a contribution to the hospital context and to the health field.

Keywords: Anguish, General hospital, Health team, Medical Psychology, Psychoanalysis.

\section{INTRODUÇÃO}

Esta pesquisa parte da atividade prática de Interconsulta realizada nos anos de 2015 e 2016 no Hospital Universitário Pedro Ernesto, hospital-escola da Universidade do Estado do Rio de Janeiro UERJ. Naquela ocasião, trabalhamos como psicólogas especializandas do Curso de Pós-graduação em Psicologia Médica e Saúde Mental. A interconsulta consiste em uma atividade que, a partir da elaboração de pedido de parecer feito pela equipe, após apreender alguma questão de ordem subjetiva do paciente ou da família, recorre aos profissionais da psicologia. Nesse contexto, recebemos a demanda para atendimento de G.J, 75 anos, diagnosticado com Linfoma Cutâneo das Células T. No atendimento, percebemos forte angústia na equipe de saúde, o que sinalizava que o pedido de escuta não se restringia apenas ao paciente que, no presente momento, encontrava-se fora de cuidados terapêuticos. Dessa forma, ao receber uma demanda, o psicólogo deve estar atento não apenas ao paciente no leito, mas, também, estender sua escuta aos familiares e a equipe de saúde. O caso de G.J foi discutido e atendido sob supervisão de Staff responsável.

\section{OBJETIVO E MÉTODO}

O objetivo do presente trabalho foi a escuta psicológica e psicanalítica no contexto hospitalar frente à angústia da equipe de saúde. A escuta singular da equipe como prática do psicólogo no contexto hospitalar assume destaque, tendo como referencial teórico, a psicologia médica e a psicanálise. Partindo desses pressupostos teórico-conceitual e da escuta singular do um a um, o método utilizado foi a pesquisa qualitativa com a observação e a escuta analítica da equipe de saúde.

Sabemos, a partir de Sigmund Freud, o valor que o estudo de caso tem para o contexto clínico e hospitalar. No presente trabalho, o estudo de caso não faz referência apenas ao paciente, mas, também, aos 
membros da equipe de saúde que, visivelmente angustiados frente ao caso de G.J, sentiam-se mal a ponto de não conseguirem a atuação desejada.

A fim de melhor ilustrar nossas experiências no contexto citado, apresentaremos fragmentos do caso ao longo da discussão.

\section{RESULTADOS}

O ambiente hospitalar traz vivências de situações traumáticas tanto para o paciente como para a família e o profissional de saúde. O profissional da psicologia atuante no hospital geral precisa permanecer atento à demanda da equipe que, em geral, refere-se ao sofrimento psíquico do paciente. No hospital isso é verificado na medida em que o paciente apresenta comportamentos que escapam à conduta médica, ou seja: choro excessivo, recusa no uso de medicação, negação diante do quadro clínico, entre outros. Contudo, o que verificamos no caso de G.J, para nossa surpresa, foram atuações na equipe responsável por atender o paciente. Assim, fica a pergunta: o que o psicólogo pode escutar frente a angustia da equipe? Há espaço para o sofrimento da equipe? Muniz e Chazan, psiquiatras estudiosos no assunto, relatam que "a Psicologia Médica tem como principal objetivo de estudo as relações humanas no contexto médico" (2009, p.49) direcionando que, neste contexto, trata-se das relações humanas e não apenas do sujeito à beira do leito causa de sofrimento.

Ao adentrarmos a enfermaria em uma primeira abordagem, percebemos algumas dificuldades da equipe, como: o manejo com relação ao caso, a falta de comunicação com os familiares do paciente e, principalmente, profissionais que constantemente se ausentavam da enfermaria para lamentar o prognóstico do caso. Nosso papel consistiu em sinalizar os profissionais em relação a possibilidade do surgimento da angústia frente à morte e, ainda, proporcionar um lugar de escuta. Freud (1916[1915]), no texto 'Sobre a transitoriedade', indica a proximidade do luto pela perda de algo ou alguém como um enigma, um daqueles fenômenos que por si só não seriam explicáveis, porém, sinaliza que é a partir dos efeitos causados naqueles que permanecem em vida que é possível rastrear algum ponto obscuro entre a conflitiva relação vida e morte. No caso de G.J apostamos na equipe, organismo vivo e causado pelo quadro clínico que se apresentava. O paciente, por si só, pouco se interessava pela psicologia.

No hospital, o adoecimento do corpo e a hospitalização funcionam como possíveis disparadores para o aparecimento da angústia. Acreditamos que a oferta do profissional da psicologia nesse contexto possa funcionar de forma que o sujeito, a equipe e a família viva as situações ao qual o ambiente hospitalar invoca como um convite ao trabalho diante do que é possível ser feito. Além disso, que estes autores possam criar recursos psíquicos para não sucumbirem diante de certos cenários que, por vezes, são arrasadores. O psicanalista Mohallen aponta que, "a criatividade do analista, na urgência, é 
fundamental. É preciso criar para produzir, com os recursos possíveis em cada situação, um convite ao trabalho". (2003, p.29). Portanto, a criação no hospital surge como um potente instrumento de ressignificação para o profissional psi e, também, para aqueles que se encorajam a falar da sua própria angústia.

\section{DISCUSSÃO}

O paciente G.J, 75 anos, internado por Linfoma Cutâneo de Células T, permaneceu no hospital por aproximadamente um ano, entre altas e reinternações. A cada retorno, uma nova enfermaria o acolhia e um novo pedido de parecer para a psicologia era enviado. O paciente sempre causou desconforto às equipes que o atendiam, o aspecto de sua pele e o mau cheiro, causava repulsa aos que se aproximavam. Em sua última internação, o caso agravou-se e as medicações já não aliviavam suas dores. A enfermagem estava desconfortável com seu cuidado e a equipe médica já dizia não ter mais o que fazer, pois não podiam aumentar as doses dos medicamentos. O paciente se encontrava em cuidados paliativos.

Ao longo de duas semanas permanecemos na enfermaria, seja para falar com os familiares ou com membros da equipe. A partir da escuta oferecida uma residente pôde dizer que, 'aquele senhor ali deitado se parece com meu pai, não consigo dar banho nele'. Freud (1929), em 'O mal estar na civilização', aponta o corpo como uma das fontes de mal estar inerente a todo e qualquer sujeito, afirma que, os ruídos produzidos pelo corpo, marcam a característica da transitoriedade. E era exatamente o que a estudante se lamentava. Em um segundo momento viemos a saber que o pai da residente estava internado em outro hospital com o diagnóstico de câncer.

Podemos perceber, então, que a resposta psicológica de um parecer médico está em localizar o ponto de partida da demanda, isto é, depurar o autor ou, os autores, da angústia. Será que a equipe tem lugar para lidar com suas próprias angústias? Com Mohallen vemos que, "O hospital é um lugar propicio a malentendidos, já que diante de muita angústia fica difícil discernir o dentro e o fora” (2003, p.29).

Logo, por vezes, observamos que o profissional de saúde aponta como demanda o atendimento do paciente sem, de fato, deparar-se com a sua própria angústia. Após esse período, o paciente veio a falecer. O alívio da equipe era visível.

\section{CONSIDERAÇÕES FINAIS}

Podemos dizer que a função do profissional da psicologia no hospital requer atenção ao paciente internado, à família e à equipe. Portanto, a oferta de tratamento da Psicologia Médica e o olhar singular da Psicanálise operam como contribuição para o contexto hospitalar e para o âmbito da saúde. 
A ação do profissional é de ser responsável por promover a assistência à Saúde Mental e o acesso da escuta diferenciada, viabilizando a abertura de novos olhares para o sujeito e sua história. Apostamos em algo que ultrapassa a abordagem organicista, visão privilegiada no ambiente hospitalar. O que escutamos diz respeito à dimensão subjetiva de cada um.

A partir da escuta ofertada, a proposta é tratar uma outra urgência: a urgência subjetiva. $O$ desafio que se apresenta para nós profissionais da escuta ativa no hospital geral é decantar a demanda que se apresenta para, só assim, ofertar uma escuta diferenciada. O principal achado deste trabalho é a percepção do sofrimento por parte da equipe, como isso é levado em conta e, principalmente, qual o lugar para a angústia dos profissionais.

Desenvolver um trabalho multidisciplinar no hospital é também lidar com as diferenças de métodos e abordagens sobre o fenômeno do sofrimento humano, reservando ao profissional o lugar de respeitar os limites de cada campo e, então, trabalhar na interseção entre as práticas.

\section{REFERÊNCIAS}

FREUD, S. (1916 [1915]). Sobre a transitoriedade. In: FREUD, S. Obras Psicológicas Completas de Sigmund Freud. Rio de Janeiro: IMAGO, vol. XIV, 1974.

FREUD, S. (1930[1929]). O mal estar na civilização. In: FREUD, S. Obras Psicológicas Completas de Sigmund Freud. Rio de Janeiro: IMAGO, vol. XXI, 1974.

MOHAllem, L. N. (2003). Psicanálise e hospital: Um tempo de criação. In: Psicanálise e Hospital 3 Tempo e Morte: Da urgência ao ato analítico. Minas Gerais: Revinter Ltda, 2003. 29p.

MUNIZ, J.R.; CHAZAN, L.F. Ensino de psicologia médica. In: Mello Filho, Julio de; Burd, Miriam \& Cols. Psicossomática hoje. 2.ed. Porto Alegre: ARTMED, 2009. 49p. 